\title{
The erosion of an ideal gully under steady state conditions
}

\author{
$\underline{\text { M. E. Roberts }}^{\text {ab }}$ \\ ${ }^{a}$ Australian Rivers Institute, Griffith University, 170 Kessels Road, Nathan, Queensland 4111 \\ ${ }^{\mathrm{b}}$ School of Mathematics and Statistics, University of Melbourne, Parkville, Melbourne, Victoria 3010 \\ Email: m.roberts2@griffith.edu.au
}

\begin{abstract}
Gullies are responsible for as much as $40 \%$ of the accelerated sediment reaching the GBR, contributing to poor water quality and impacting the health and resilience of the Reef. Improving water quality on the GBR is essential to provide the best opportunity to recover from past events and meet the challenges of climate change. The Australian and Queensland Governments aim to reduce sediment delivery to the Reef by $25 \%$ as part of the Reef 2050 Water Quality Improvement Plan 2050. Given the disproportionate contribution of gullies to the total sediment budget, reducing gully erosion will be an important part of meeting this target. The Prosser Report (2018) has identified process-based models of gully erosion as important to support the strategic remediation of gullies. Previous models have employed empirical or conceptual approaches, which are not well suited to be adapted to representing interventions to provide localised decision support. This paper presents a first step in the development of a locally focussed, process-based model of gully erosion that is capable of representing gully interventions.
\end{abstract}

The focus on water quality impacts on the GBR motivates the modelling focus on the concentration of sediment within the water column rather than on the evolution of the gully system. Gully erosion is therefore modelled using conservation of mass arguments, with entrainment of sediment from the gully walls and bed acting as a sediment source and deposition of sediment as a sink. The rate of entrainment is determined by balancing the power available to do work on the gully bed with the power required to entrain. The power available to do work on the gully is due to the stream- and waterfall-power of the system resulting from the loss of potential energy of the flow as it loses height. Adapting the approach of Hairsine and Rose $(1992 \mathrm{a}, \mathrm{b})$ we introduce the concept of a soil cohesiveness factor, which represents the power required to overcome the cohesion of the sediment to enable it to be entrained. Together with a static friction term, this represents the streamflow threshold, the minimum amount of power required for entrainment to occur.

A key feature of this model is the inclusion of a depositional layer and the concept of re-entrainment after the model of Hairsine and Rose (1992a,b). Steady-state solutions for the area encompassed by the depositional layer are explored, which demonstrates that the power available to erode cannot be independent of the concentration and flow conditions. A sediment carrying capacity is therefore introduced, providing a simple mechanism to represent the energy requirements of transporting sediment in suspension. The adapted model is explored under the assumptions of a highly erosive bed, and shown to provide the expected behaviour. Exploration of the model demonstrates that the assumptions of a depositional layer, particularly at steady state, requires further consideration. The aerial approach to modelling the depositional layer, although consistent with observations at the laboratory scale, appears not to extend to natural high-flow events. This analysis suggests that an alternative modelling framework to capture the mechanism of re-entrainment is necessary.

The developed model is suitable to explore gully erosion impacts on water quality and the potential benefits of different interventions. We illustrate how different interventions can be represented in the model, however parameterisation to different interventions is yet to be undertaken. Future work will focus on improving the representation of the depositional layer, validating the model against observations, and parameterising the model including the representation of interventions.

Keywords: Gullies, erosion, process-model, Great Barrier Reef, 


\section{INTRODUCTION}

The world heritage listed Great Barrier Reef (GBR) is under threat. Climate change and poor water quality are placing the reef under unprecedented stress. Excess sediments and nutrients transported from the GBR catchment to the lagoon reduce water quality, leading to a variety of negative outcomes for the reef. Poor water quality has been linked to the loss of seagrass habitat (Wooldridge, 2017), algal blooms, coral death, reduced coral recruitment, and Crown of Thorns Starfish outbreaks (Brodie et al., 2008). Reducing synergistic impacts from poor water quality is essential to provide the GBR with the opportunity to recover from past impacts and improve its resilience.

Erosion from gullies is responsible for as much as $40 \%$ of the accelerated sediment delivery to the GBR (Brooks et al. 2018). Reducing erosion from gullies therefore provides an opportunity to make significant advances in meeting the Australian and Queensland Governments' water quality targets for a $25 \%$ reduction in sedimentation for the GBR lagoon (2018b). Moreover, as sediment acts as a transport mechanism for bioavailable nutrients, reducing gully erosion will also make progress towards the targets for reduced particulate and dissolved nutrients.

Gully erosion is a focal point for activity to improve water quality on the GBR. In addition to the target of $90 \%$ of grazed lands being managed under 'best management practice' (Australian and Queensland Governments. 2018b), field studies testing different interventions, and measuring their effectiveness, are underway (e.g. National Environmental Science Program Project 3.1.7 ). The effectiveness and cost of different interventions is likely to vary considerably, by location, gully type, and synergistic effects in connected regions.

Improved mathematical models for gully erosion are required to support decision making for gully rehabilitation (Prosser, 2018). Operational models of gully erosion are limited. One example, widely applied in Australia, is the conceptual SedNet model and its extension Dynamic SedNet. Dynamic SedNet is used as part of the Paddock to Reef Modelling and Monitoring program to inform progress towards water quality targets as part of the GBR Report Cards (Australian and Queensland Governments, 2018a; Prosser, 2018). SedNet, and Dynamic SedNet, were designed to operate over large spatial and temporal scales to quantify the expected average erosion from a region, and is not suitable to be applied at the scale of individual gullies or gully systems over short time-spans. Limitations in the use of Dynamic SedNet to investigate local scale-dynamics, for which it was not designed, has lead to a call for more physically based models to better inform gully intervention strategies (Prosser, 2018).

An alternative to the SedNet model is the process based model of Hairsine and Rose. Motivated by laboratory observations, Hairsine and Rose presented a physically based model of erosion for sheet (1992a) and rill (1992b) flow, which was later extended to gullies (Rose et al. 2014). We adapt their approach as a first-step towards our model of gully erosion that captures the driving physical process of erosion, allowing for the representation of interventions via the physical parameters of the model directly.

This paper is organised as follows. A brief introduction to gullies is presented in Section 2, and the model is introduced in Section 3. Steady-state solutions are given in Section 4. Exploration of this model demonstrates significant limitations in the modelling approach, and highlights gaps in our understanding of the erosion processes as they apply to large flow events in gullies. We explore some modelling options in Section 5 and provide a short discussion of considerations for representing interventions in Section 6 before a short conclusion highlighting future directions for research in Section 7

\section{Gullies}

Gullies are features in the landscape formed by running water eroding into the soil structure. They are distinguished from rills by their depth, with gullies being defined as greater than $30 \mathrm{~cm}$ deep. We omit a detailed description of gullies, and the complex associated geomorphic processes of their development and evolution, and instead focus on the features of gully development addressed by the developed model.

We consider linear gullies, see Fig. 1. Runoff enters the gully predominantly via the gully head, cascading into the gully similar to the action of a waterfall. The gully 'waterfall' erodes sediment at the head, leading to head-cut retreat and the linear growth of the gully. Below this waterfall region, the runoff flows through the gully channel scouring the base and walls. This scouring action leads to erosion of the floor (deepening the gully) and walls (widening the gully). Within the waterfall region deposition of sediment is negligible, however below the waterfall deposition can result in a build-up of sediment upon the gully floor. Undercutting at the gully walls leads to mass collapse events, however this is not considered here. 
M. E. Roberts, The erosion of an ideal gully under steady state conditions
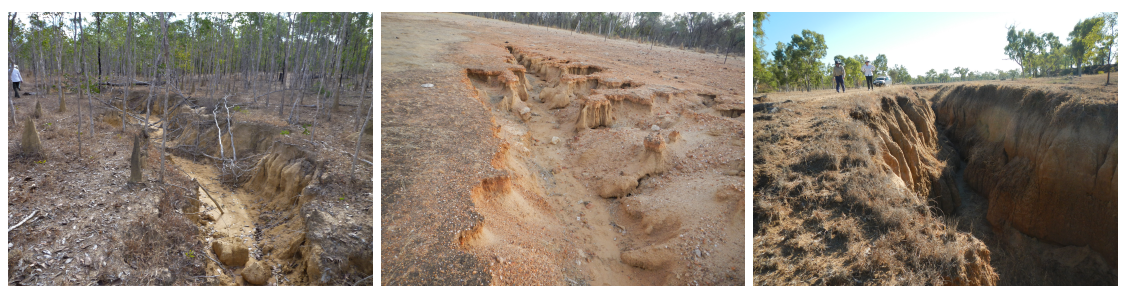

Figure 1. Examples of linear gullies within the GBR catchments. Images (c) 1- R Thwaites; 2 \& $3-\mathrm{A}$ Brooks
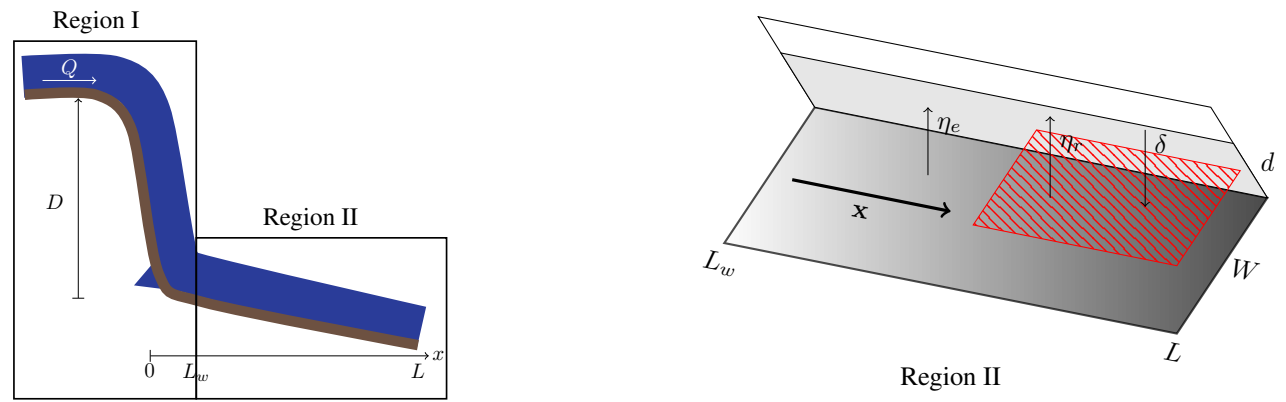

Figure 2. Geometry of the ideal gully. The sediment concentration $C(x, t)\left[\mathrm{kg} / \mathrm{m}^{3}\right]$ satisfies the conservation of mass equation, which is to be solved within the bounded domain $x \in[0, L]$, split into the two regions for convenience. Region I encompasses the gully waterfall $\left[0, L_{w}\right)$, while Region II the gully channel $\left[L_{w}, L\right]$. The gully is of constant slope. The flow within the gully is of constant flux $Q$ with depth $d[m]$, and width $W$ $[\mathrm{m}]$. Sediment is entrained from the walls and floor at rate $\eta_{e}[\mathrm{~kg} / \mathrm{ms}]$ and re-entrained at rate $\eta_{r}[\mathrm{~kg} / \mathrm{ms}]$. Sediment is deposited out at rate $\delta[\mathrm{kg} / \mathrm{ms}]$ forming the depositional layer (shown in red).

\section{THE MODEL}

Consider an ideal homogeneous gully of rectangular geometry and constant shallow slope. The gully is situated such that rain events will generate a runoff sufficient to overcome the resistance of the soil to erosion. We assume that the catchment area for a gully as well as the gully dimensions are constant throughout an event. Fig. 2 shows the geometry of our ideal gully.

We seek to determine the net sediment mass delivered to the stream network as a result of gully erosion. That is, for a given known runoff flux and concentration of sediment entering the gully, we seek the sediment concentration exiting the gully system. The concentration of sediment within the water column is given by the one-dimensional conservation of mass equation, subject to a sediment source due to the entrainment of sediment within the gully, and a sediment sink due to deposition processes. The gully system is divided into two regions, the waterfall region near the gully head (Region I), $0 \leq x<L_{w}$, and the gully channel (Region II) $L_{w} \leq x \leq L$. Within each region the one-dimensional conservation of mass for the mean sediment concentration $C$ with entrainment $\eta\left[\mathrm{kg} / \mathrm{m}^{2} \mathrm{~s}\right]$ and deposition $\delta\left[\mathrm{kg} / \mathrm{m}^{2} \mathrm{~s}\right]$ is

$$
\frac{\partial C}{\partial t}+\frac{Q}{W d} \frac{\partial C}{\partial x}=\frac{1}{d W}(\eta-\delta)
$$

where $W[\mathrm{~m}]$ is the constant gully width, $Q\left[\mathrm{~m}^{3} / \mathrm{s}\right]$ is the constant volumetric flux of water through the gully, and $d[m]$ is the depth the flow within the gully. This is solved subject to the initial condition $C(x, 0)=0$, and boundary conditions for each region of known sediment concentration of the runoff $C(0, t)=C_{W 0}(t)$, and $C\left(L_{W}, t\right)=C_{C 0}(t)$. The boundary condition for the channel region is given by solution of the conservation of mass equation in the waterfall region. The depth of flow, which is less than the gully depth $D$ [m], is related to the runoff flux via Manning's Equation $Q=\frac{1}{n} \frac{(d W)^{5 / 3}}{(2 d+W)^{2 / 3}} \sqrt{S}$ where $n\left[s / m^{1 / 3}\right]$ is Manning's Roughness Coefficient, and $S$ is the slope.

We consider rainfall-runoff events that generate a known flux of water through the gully. The water depth associated with this flux is sufficient to shield the gully floor from rainfall-detachment. That is, we neglect rainfall-detachment and focus on detachment due to the power available due to runoff alone. This assumption 
is not unreasonable, rainfall detachment applies only where the water depth is less than approximately 3 times the diameter of the raindrop. The sediment loads able to be transported by such low flow events are small in comparison with the transport capacity of higher flow events, and therefore such events are expected to have a negligible impact on the GBR relative to runoff driven events. We note that rainfall-detachment prior to a high-flow event, particularly for highly dispersive soils, will reduce the resistance of the soil to erosion, however do not model this activity explicitly.

We adopt a streampower argument to relate the energy available to do work against the gully floor and walls with the rate of entrainment. The power available for erosion is given by the rate of loss of potential energy in the flow. The flow loses potential energy due to the loss of height as it flows over the gully wall (Region I) or downslope (Region I \& II).

The power available to do work on the gully surface per unit area due to the downslope flow is given by the streampower $\Omega\left[W / \mathrm{m}^{2}\right]$. Assuming that the streampower acts equally across the wetted perimeter of the gully $\Omega=\rho g S Q / W+2 d$, where $\rho\left[\mathrm{kg} / \mathrm{m}^{3}\right]$ is the density of the flow, $g\left[\mathrm{~m} / \mathrm{s}^{2}\right]$ is gravitational acceleration, and $Q$, $S, d$ and $W$ are the previously defined runoff flux, and gully slope, depth and width. The power available to do work on the gully floor due to the waterfall at the head is given by the waterfall power $\Psi=\rho g Q D(x) / W L_{w}$, $\left[W / m^{2}\right]$ assuming that the waterfall acts equally across the floor of the gully in Region I. We note that this neglects scouring of the gully wall at the head, and therefore represents an under-estimate of the erosion expected.

The power available to erode the gully in each region, which is some fraction $k$ of the total waterfall or streampower (as energy is also dissipated via frictional heating, noise etc.), is equated with the power required to entrain sediment. We develop this argument for Region II, the gully channel, however it applies equally to Region I.

Adapting the approach of Hairsine and Rose (1992a, b), we introduce $J$, the power required to overcome the cohesiveness of the soil, and $F$ the power required to overcome static friction. $F+J$ may be considered some streampower threshold, below which erosion will not occur. Therefore $k \Omega-F-J$ is the power available to entrain sediment within the water column. This relationship also provides a criteria for erosion, if $k \Omega-F-J \leq$ 0 erosion will not occur, and the concentration of sediment exiting the gully will be less than or equal to the concentration entering the gully (due to deposition within the gully).

The power required to entrain sediment to a height $h$ is given by $\eta\left(\frac{\sigma-\rho}{\sigma}\right) g h$, where $\sigma\left[\mathrm{kg} / \mathrm{m}^{3}\right]$ is the density of the sediment and $\eta\left[\mathrm{kg} / \mathrm{m}^{2} \mathrm{~s}\right]$ is the rate of entrainment per unit area. Balancing the power available for entrainment with the power required for entrainment gives

$$
\eta=\left\{\begin{array}{l}
(k \Omega-J-F) \frac{\sigma}{(\sigma-\rho) g h}, \quad k \Omega>J+F \\
0, \quad k \Omega \leq J+F .
\end{array}\right.
$$

As sediment is transported through the gully within the water column some of that sediment will be deposited out to form a layer atop the original sediment. (Note that deposition is assumed negligible within Region I.) This layer of recently deposited sediment will be cohesion-less $(J=0)$ and therefore easier to erode than the original sediment. We adopt the convention of Hairsine and Rose and introduce the concept of a depositional layer, which covers a proportion $a(x, t)$ of the gully floor. Entrainment from this layer is termed "re-entrainment" and indicated by the subscript $r$. For clarity, entrainment of the original soil is simply termed "entrainment" and is indicated by the subscript $e$. Re-entrainment is constrained to the depositional layer, which forms on the floor of the gully (Region II only), while entrainment occurs from the un-covered proportion of the gully floor and the portion of the gully walls submerged by the flow. Thus entrainment due to the original sediment and the deposited layer per unit length of gully are given by

$$
\begin{aligned}
& \eta_{e}=\frac{[(1-a) W+2 d]}{W+2 d}(k \Omega-J-F) \frac{\sigma}{(\sigma-\rho) g h}, \\
& \eta_{r}=\frac{a W}{W+2 d}(k \Omega-F) \frac{\sigma}{(\sigma-\rho) g h},
\end{aligned}
$$

recalling that we consider only erosive flows, that is $k \Omega \geq J+F$.

This model of erosion introduces a number of assumptions, which are problematic for large-flow events, as will be shown in Section 4. Importantly, the model assumes that the streampower proportion $k$ is independent of the flow, and that the process of entrainment is independent of the concentration of the eroding flow. 
The process of deposition is modelled using the simple relationship

$$
\delta=b C w_{s}
$$

where $b$ [nondim] is the ratio of the mean concentration of the flow $C$ to the concentration of the flow at the base and $w_{s}[\mathrm{~m} / \mathrm{s}]$ is the settling velocity of the particles. The settling velocity can be calculated theoretically, for example using Stokes Law, or taken from observations. During high flow events, the flow is likely to be turbulent, therefore the best estimate of the concentration of the flow at the base is the mean concentration $C$. We therefore use $b=1$ in our examples, however retain the flexibility to impose a concentration gradient.

\section{STEAdy-STATE Solution}

Hairsine and Rose (1992a) identified that under constant flux an equilibrium situation is approached whereby the proportion of the gully covered by recently deposited sediment is constant. We therefore investigate steadystate solutions under the assumption of $a(x, t)=a(x)$.

Such steady-state conditions arise when the rate of deposition is equal to the rate of re-entrainment, $\delta=\eta_{r}$, which implies

$$
C(x)=\frac{a(x)(k \Omega-F)}{b g h w_{s}} \frac{\sigma}{\sigma-\rho} \frac{W}{W+2 d},
$$

and an equilibrium balance between the size of the depositional layer and the concentration within the flow. The rate of erosion, and hence the concentration of the flow, will be at its theoretical maximum when the depositional layer encompasses the entire gully floor, that is $C_{\max }=\left.C\right|_{a=1}$. For low streampowers, $C_{\max }$ appears reasonable, however as the streampower increases to even moderate values the concentrations rapidly become unrealistic. For the parameters used for Fig. 3 a flow depth of $20 \mathrm{~cm}$ gives $C_{\max }=1087.1$, which equates to a sediment volume (per cubic metre of water) of $\approx 61 \%$. Increasing the flow depth to $1 \mathrm{~m}$ gives $C_{\max }=1591.13$ and an unrealistic sediment volume of $90 \%$. Limiting the sediment concentration to a more realistic (but still high) $25 \%$ by volume equates to flow depths of no more than $4 \mathrm{~cm}$. Although parameter values selected for the settling rate $w_{s}$, concentration gradient $b$, and static friction component $F$ could all arguably be higher, or the streampower proportion value $k$ lower, the values required to constrain the sediment concentration to feasible levels for a broad range of gullies and flow events are unrealistic, especially since our assumption that the average sediment entrainment height scales linearly with the flow depth $h=d / 2$ likely underestimates the entrainment rate significantly for large flows.

As the maximum sediment concentrations obtained are unrealistic, we conclude that the proposed model for gully erosion is incorrect at the scales under consideration, and that some critical component of the physical processes is neglected by this model. We propose that some mechanism exists that limits erosion as it approaches the natural carrying capacity of the flow and explore this concept in Section 5 below. Such a limitation in the entrainment term could arise due to a concentration dependent reduction in the available streampower, or an inability of the flow to hold the additional sediment.

We further question the concept of a steady-state scenario with a depositional layer potentially encompassing the entire gully bed. This gully configuration was modelled after Hairsine and Rose (1992a, b), which underlies the model employed to model erosion of the Bremer gully in Rose et al. (2014). Where the depositional layer encompasses the entire gully bed, that is $a=1$, the sediment concentration of the flow must be constant throughout the length of the gully, that is $C(x)=C_{\max }$, as described above. However, if the sediment concentration is constant throughout the length of the gully, then the left-hand side of the conservation of mass equation, (1), is zero, which therefore requires that $\eta_{e}+\eta_{r}+\delta=0$. Under steady-state conditions we have, by definition, $\eta_{r}=\delta$, which therefore requires $\eta_{e}=0$. For the case of flow along a plane (sheet flow), for which this theory was first developed, this follows naturally from the assumption that $\eta_{e}=0$ when $a=1$ due to shielding from the depositional layer. For the case of concentrated flows, rills or gullies, the expected erosion of the walls violates this condition, which calls into question the feasibility of this scenario.

\section{SEDIMENT CARRYING CAPACITY FOR A HIGHLY EROSIVE GULLY}

We adopt the concept of a carrying capacity, common in population modelling, and apply it to our entrainment terms (3), under the assumption that the rate of entrainment is limited by the concentration of the flow. We further assume that our gully is highly erosive and $k \Omega \gg J+F$. We neglect the differences between the depositional and original layer and assume a single source of sediment across the walls and floor with no 
M. E. Roberts, The erosion of an ideal gully under steady state conditions
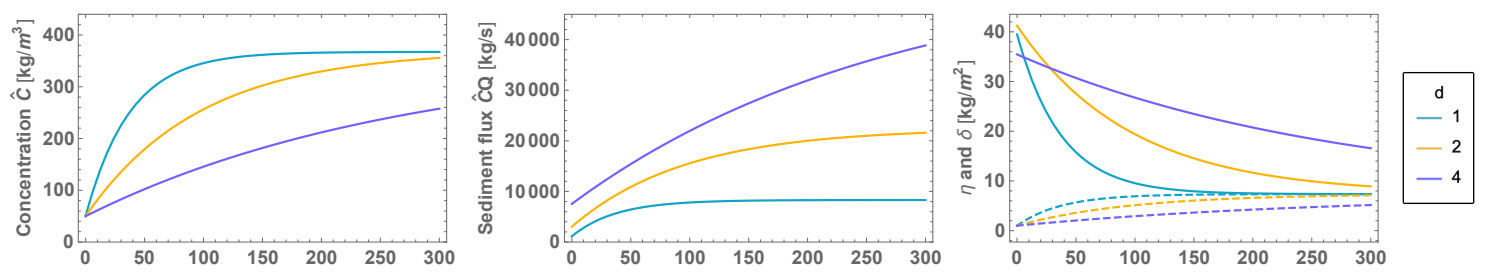

Figure 3. Sediment concentration, $\hat{C}$, and flux, $\hat{C} Q$, and rates of entrainment $\eta$ and deposition $\delta$ for a $5 \mathrm{~m}$ wide gully and selected flow depths. The depths correspond to runoff fluxes of $Q=22,60$, and $150 \mathrm{~m}^{3} / \mathrm{s}$. Parameters are: $\sigma=1760, \rho=997, b=1, w_{s}=0.02, S=0.02, n=0.025, g=9.81$ and $C_{C 0}=50$.

effective cohesive resistance to erosion. Under these conditions the simplified entrainment is

$$
\eta=(W+2 d) k \Omega \frac{\sigma}{(\sigma-\rho) g h}\left(\frac{C^{*}-C}{C^{*}}\right), \quad k \Omega \gg J+F
$$

where $C^{*}\left[\mathrm{~kg} / \mathrm{m}^{3}\right]$ is the carrying capacity of the flow. By definition, the transport capacity is now $C_{\max }=$ $C^{*}$. A comment on nomenclature - we differentiate between the carrying capacity and transport capacity of the flow in the following way. The transport capacity refers to the theoretical maximum sediment concentration for a specific gully configuration (width, slope, flux etc.), while the carrying capacity refers to the ability of a volume of water to contain the sediment. As the sediment volume per unit flow volume $(=C / \sigma)$ approaches one, the concept of erosion ceases to apply, becoming debris flows, slurry flows and ultimately landslides, which is not the focus of this paper.

One consequence of this assumption is that a steady depositional layer will not arise. This is because as $C \rightarrow C^{*}$ re-entrainment goes to zero, while deposition approaches its maximal value $\delta=b C^{*} w_{s}$. This raises further questions about the feasibility of a steady state depositional layer during high flow events. Avoiding the singularity as $C \rightarrow C^{*}$ necessitated the highly erosive approximation introduced above in (6).

For simplicity we apply the transformation $X=x-L_{w}$ such that Region II is now the domain $\left[0, L-L_{w}\right]$, and indicate the concentration on this transformed domain as $\hat{C}$. The dynamic steady state, given by $\partial \hat{C} / \partial t=0$ in (1) and with $C(L)=\hat{C}(0)=C_{C 0}$ is therefore

$$
\begin{aligned}
\hat{C}(X)=C_{C 0} \exp \left[-\frac{W X}{Q}\left(b w_{s}+\right.\right. & \left.\left.\frac{\sigma}{\sigma-\rho} \frac{k \Omega-F}{C^{*} g h}\right)\right] \\
& +\frac{C^{*}(k \Omega-F)\left\{1-\exp \left[-\frac{W X}{Q}\left(b w_{s}+\frac{\sigma}{\sigma-\rho} \frac{(k \Omega-F)}{C^{*} g h}\right)\right]\right\}}{b C^{*} g h w_{s}(\sigma-\rho) / \sigma+(k \Omega-F)} .
\end{aligned}
$$

Fig. 3 shows the sediment concentration, sediment flux, and entrainment and deposition rates within a gully for three exemplar flow depths. These results illustrate the role of the carrying capacity, assumed to be $25 \%$ by volume, on constraining the concentration within the gully. Despite the imposed restrictions on $\hat{C}$, these results point to high sediment fluxes. Sediment fluxes exceeding $10 t / s$ are indicated for high flow events even for short gullies $(<15 \mathrm{~m})$, however we caution that the parameters used in this study are yet to be validated and therefore these values should not be considered to hold predictive power for any specific event. As $X \rightarrow \infty$ an equilibrium between the entrainment and deposition is reached and $\hat{C} \rightarrow \hat{C}_{\max }=\frac{C^{*} k \Omega}{b g h w_{s} C^{*}(\sigma-\rho) / \sigma+k \Omega}$. This represents a steady state between total entrainment $\eta_{e}+\eta_{r}$ and deposition, as opposed to re-entrainment $\eta_{r}$ and deposition. Thereby permitting the mass of sediment within the depositional layer to increase over time with $\eta_{r}<\delta$. Gullies have been observed to have depositional layers that vary significantly in depth from event to event. This suggests that an aerial argument for the depositional layer, which does not account for a growing sediment mass, is likely inappropriate to model gullies subject to high flow events.

\section{DISCUSSION - REPRESENTING INTERVENTIONS}

The motivation for developing a process-based model of gully erosion is to enable interventions to be represented to better inform decision making. Interventions to reduce erosion are diverse, but target a combination 
of three factors: runoff, erosive resistance and deposition. Slowing the flow of water, for example via porous check dams, decreases the water flux $Q$, thereby reducing the amount of power available to erode $k \Omega$. Increasing the erosive resistance of the soil, $J$, for example with improved ground-cover, will have a similar effect, as a greater power will be required in order to entrain the same mass of sediment. Deposition, being a function only of the concentration near the bed and the settling velocity, cannot be directly influenced. However, reducing the water velocity will increase the retention time of the water and hence allow for more sediment to settle out before reaching the stream.

Determining the physical parameters of different soil structures and how different interventions inter-relate and effect these parameters will be critical to operationalising this model. The time-evolution of the benefits of interventions must be considered to ensure fair comparison between different intervention options (Roberts and Ellis, 2019). Consider for example natural re-vegetation facilitated via stock exclusion versus active revegetation (planting) - it is reasonable to assume that the active re-vegetation (higher cost) will achieve the desired ground or tree-cover quicker than if left to recover unassisted (lower cost).

\section{Conclusions}

This paper presents a preliminary model for gully erosion that can represent management interventions to reduce erosion. The high-flow events common to gully erosion in the Great Barrier Reef catchments introduces additional complexities over rill erosion, even for similar geometries. Field data is required to validate and parameterise the model, and to explore the nature of the steady state solution and the characteristics of the depositional layer. Future work will focus on exploring these concepts.

\section{ACKNOWLEDGMENTS}

This research is proudly supported by the Queensland Government through the Queensland Water Modelling Network. I would like to thank B. Yu (Griffith University), E. Tomas and A. Garzon-Garcia (Department of Environment and Science), M. Silburn, S. Darr and D. Waters (Department of Natural Resources, Mines and Energy) and R. Bartley (CSIRO) for their valuable insights.

\section{REFERENCES}

Australian and Queensland Governments (2018a). Paddock to Reef Integrated Monitoring, Modelling and Reporting Program.

Australian and Queensland Governments (2018b). Reef 2050 Water Quality Improvement Plan 2017-2022.

Brodie, J., J. Binney, K. Fabricius, I. Gordon, O. Hoegh-Guldberg, H. Hunter, P. OReagain, R. Pearson, M. Quirk, P. Thorburn, J. Waterhouse, I. Webster, and S. Wilkinson (2008). Synthesis of evidence to support the Scientific Consensus Statement on Water Quality in the Great Barrier Reef. Technical report, State of Queensland.

Brooks, A. P., J. Spencer, N. Doriean, T. J. Pietsch, and J. Hacker (2018). A comparison of methods for measuring water quality improvements from gully rehabilitation in Great Barrier Reef catchments. In Proceedings of the th Australin Stream Management Conference, Hobart, Australia, pp. 1-8.

Hairsine, P. B. and C. W. Rose (1992a). Modeling water erosion due to overland flow using physical principles: 1. Sheet flow. Water Resources Research 28, 237-243.

Hairsine, P. B. and C. W. Rose (1992b). Modeling water erosion due to overland flow using physical principles: 2. Rill flow. Water Resources Research 28(1), 245-250.

Prosser, I. P. (2018). Improving how gully erosion and river sediment transport processes are represented in Queensland catchment models. https://www.des.qld.gov.au/science/documents/ qwmn-gully-erosion-processes-report.pdf.

Roberts, M. E. and R. Ellis (2019). Effects of temporal variation in sediment reduction following improved land management practices on end-of-system delivery: A modelling investigation of a grazed catchment in Queensland, Australia. In WIT Transactions on Ecology and the Environment, pp. 9-20. Southampton UK: WIT Press.

Rose, C. W., B. Yu, D. P. Ward, N. E. Saxton, J. M. Olley, and E. K. Tews (2014). The erosive growth of hillside gullies. Earth Surface Processes and Landforms 39(15), 1989-2001.

Wooldridge, S. A. (2017, January). Preventable fine sediment export from the Burdekin River catchment reduces coastal seagrass abundance and increases dugong mortality within the Townsville region of the Great Barrier Reef, Australia. Marine Pollution Bulletin 114(2), 671-678. 